\title{
ESTIMATION OF STRESS INTENSITY FACTORS IN TUBULAR K-JOINTS USING DIRECT AND INDIRECT METHODS
}

\author{
S.T. Lie ${ }^{1, *}$, T. $\mathrm{Li}^{2}$ and Y.B. Shao ${ }^{3}$ \\ ${ }^{1}$ School of Civil and Environmental Engineering, Nanyang Technological University, \\ 50 Nanyang Avenue, Singapore 639798 \\ ${ }^{2}$ Maritime Research Centre, Nanyang Technological University, \\ 50 Nanyang Avenue, Singapore 639798 \\ ${ }^{3}$ School of Civil Engineering, Yantai University, Yantai City 264005, P. R. China \\ *(Corresponding author: E-mail: cstlie@ntu.edu.sg)
}

Received: 9 February 2011; Revised: 15 June 2011; Accepted: 29 June 2011

\begin{abstract}
The stress intensity factors at the deepest point and at the crack ends of a surface crack in a tubular $\mathrm{K}$-joint are calculated by direct and indirect methods. In the direct method, the surface crack is modelled explicitly. An automatic mesh generator is developed to produce a well-graded mesh around the crack region. This is achieved by using five types of elements. Thereafter, the stress intensity factors of a surface crack located anywhere along the weld toe at the joint intersection are calculated using the $J$-integral method. The computed values had been verified by experimental test results. In the indirect method, the stress intensity factors are estimated by the T-butt solutions used in conjunction with the stress concentration factors (SCFs) and degree of bending (DOB) of the uncracked tubular $\mathrm{K}$-joint. In this study, a total of 1024 models, covering a wide range of geometrical parameters and crack shapes, have been selected and analyzed. Both approaches are able to produce a safe estimation of stress intensity factors at the deepest point of the surface crack. However, the indirect method is found to be extremely conservative; it overestimates the stress intensity factor values by as much as $190.4 \%(\beta=0.5, \gamma=30, \tau=0.5, a / T=0.1, c / a=5)$ at the deepest point, and $390.7 \%(\beta=0.4, \gamma=30, \tau=0.5, a / T=0.5, c / a=8)$ at the crack ends of the surface crack respectively.
\end{abstract}

Keywords: Direct method, Indirect method, $J$-integral method, Mesh generator, Stress intensity factor, Surface crack, Tubular K-joint

\section{INTRODUCTION}

Tubular K-joints used in the offshore structures are always subjected to cyclic loads caused by seawater wave and wind, and hence fatigue failure is a very common phenomenon. It is crucial for structural engineers to be able to estimate the static ultimate strength and the residual life of these damaged joints when surface cracks are discovered during in services. The most effective method to analyze any cracked tubular joint is to use the fracture mechanics approach, based on accurate estimation of stress intensity factors at critical points along the crack front.

In the finite element analysis, the accuracy and convergence of the computed stress intensity factors depend very much on the type of elements, mesh quality, mesh refinement, integration schemes and weld shape modelling around the crack front. It has always been a daunting task to model a true accurate 3D surface crack located along the weld toe in any tubular joint. Some researchers (Cao et al. [1], Bowness and Lee [2]) used two types of elements to simulate the crack front where 3D prism singular and hexahedral elements were used to model the crack front and the field far away from it.

Because of these reasons and as far as the authors are aware, there is no such automatic mesh generator currently available for cracked CHS tubular joints. Therefore, a completely new automatic mesh generator has been developed and improved for this purpose in the past few years (Lie et al. [3], Lie et al. [4], Shao and Lie [5], Shao et al. [6]). This technique uses a sub-division technique whereby the entire K-joint shown on Figure 1 is divided into distinct zones. When a tubular K-joint is subjected to balanced axial loading, the crack generally occurs at the crown location and it is symmetrical about this point. In each zone, the mesh is generated and checked separately. After the 
mesh of all the zones have been completed, they are merged together to form the complete model (Figure 1). In the cracked region, five types of elements, i.e. hexahedral, prism, quarter-point collapsed prism, tetrahedron and pyramid elements, are used to model the crack zone (Figure 2), and the other zones of a K-joint. To verify the convergence of these stress intensity factors, the mesh density is doubled as shown in Figure 3. The detailed modelling procedure can be found in (Lie et al. [3], Lie et al. [4], Shao and Lie [5]).
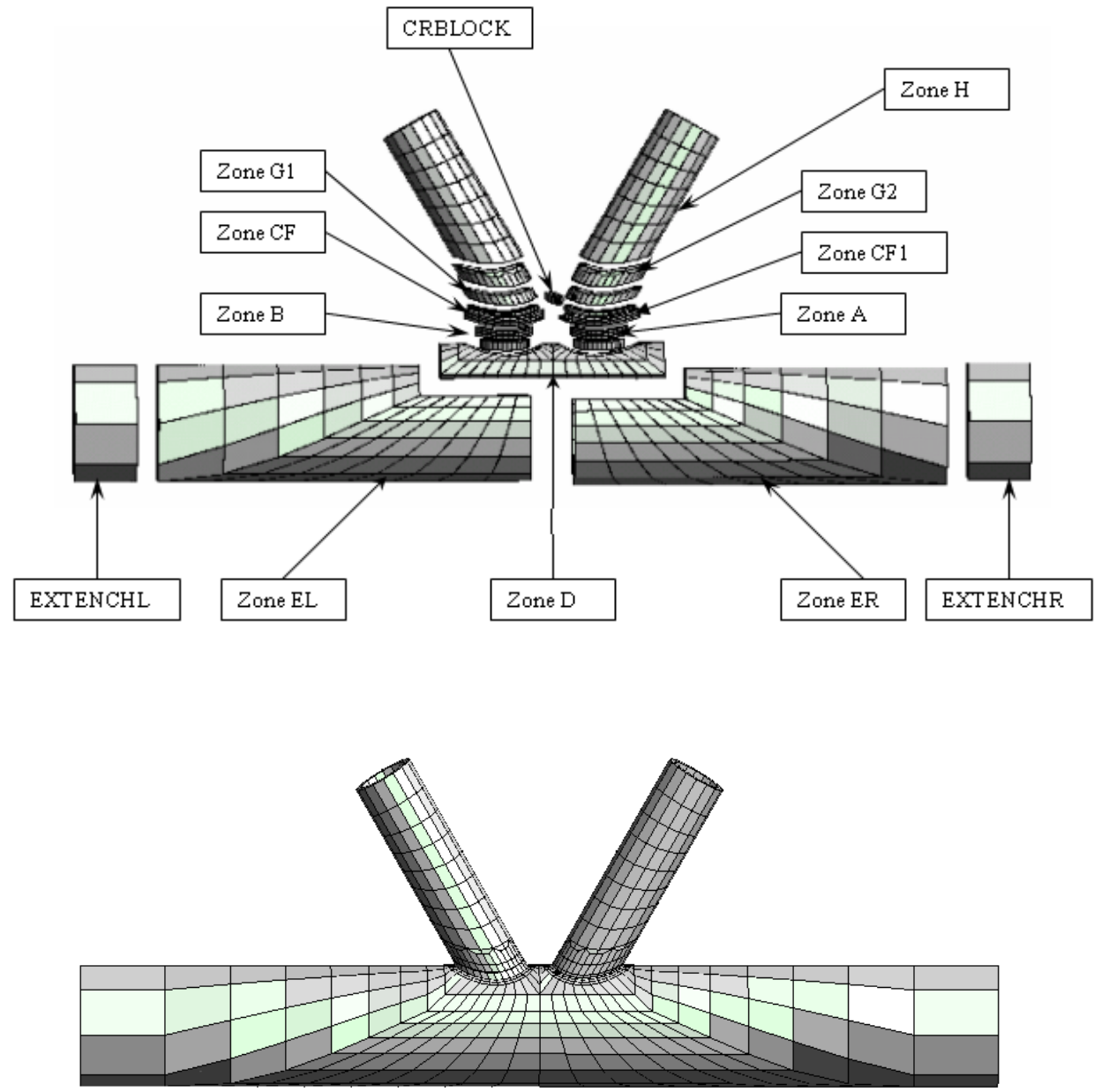

Figure 1. Sub-zone Technique used for a Tubular K-Joint

The generated finite element model of the $\mathrm{K}$-joint has been proven to produce even very accurate Mode-II $\left(K_{\mathrm{II}}\right)$ and Mode-III $\left(K_{\mathrm{III}}\right)$ stress intensity factor values along the crack front (Figure 4$)$. For the doubled mesh density, the Mode-I $\left(K_{\mathrm{I}}\right)$ stress intensity factors are recalculated and plotted along the crack front as shown in Figure 5. It can be seen that good agreement between the two sets of results demonstrates the convergence. These computed stress intensity factors had also been validated experimentally where a full-scale K-joint specimen shown in Figure 6 was fatigue tested to failure under axial tension and in-plane bending loads (Figures 7 and 8). The crack growth rate at the deepest point, $\mathrm{d} a / \mathrm{d} N$, was recorded from the experimental measurements (please refer to Lie et al. [7]). The experimental stress intensity factors were then deduced from Paris' equation, and are plotted in Figure 9 together with $K_{\mathrm{I}}, K_{\mathrm{II}}, K_{\mathrm{III}}$ and $K_{\mathrm{e}}$ values. The detailed validation procedure can be found in (Lie et al. [7]). Hence, the present mesh generation technique is shown to be able to produce accurate stress intensity factors at the deepest point of a surface crack in any tubular K-joint. 

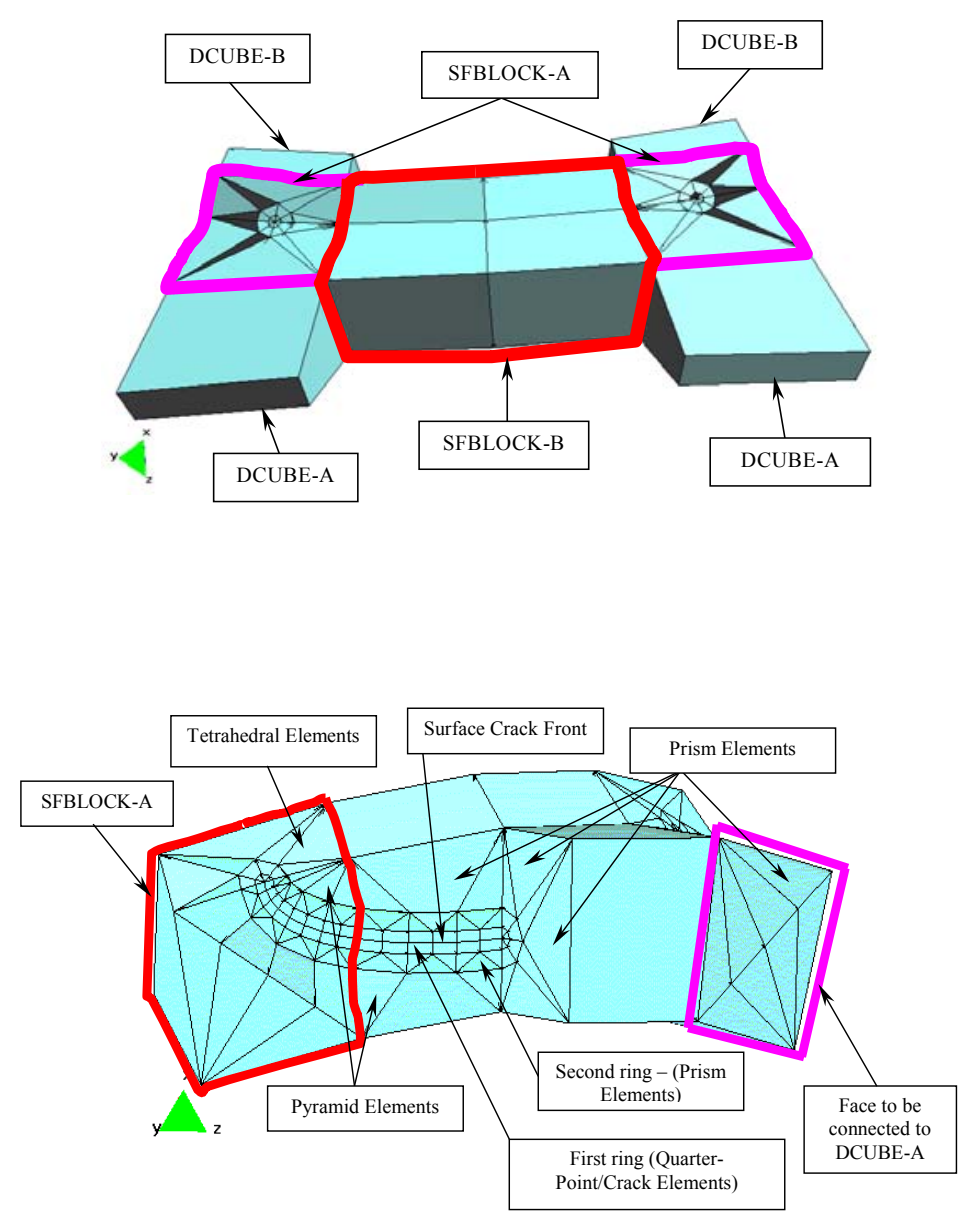

Figure 2. Detailed Mesh of the Surface Crack

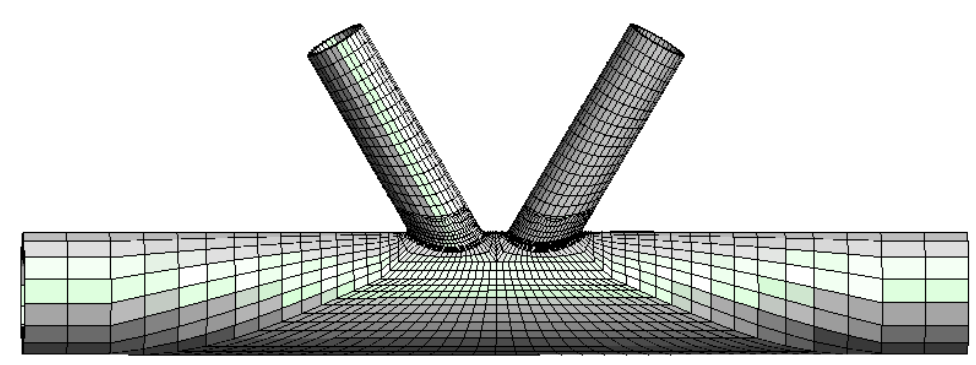

Figure 3. Doubled Mesh Density of the K-joint 


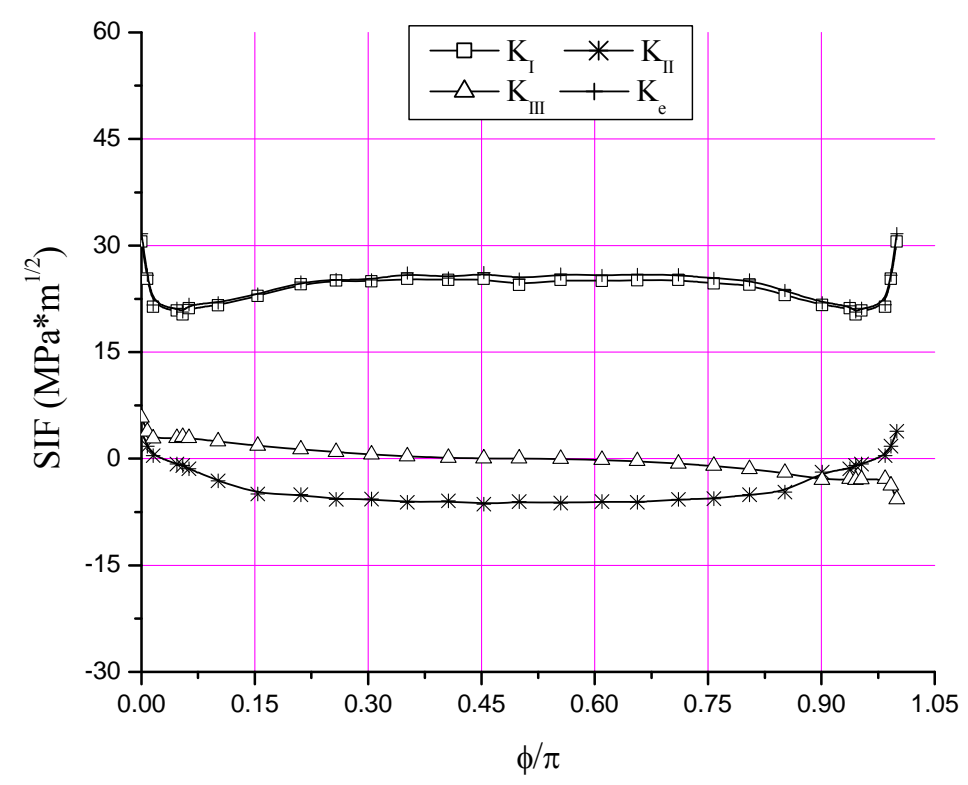

Figure 4. Typical $K_{\mathrm{I}}, K_{\mathrm{II}}, K_{\mathrm{III}}$ and $K_{\mathrm{e}}$ Stress Intensity Factor Values along the Crack Front

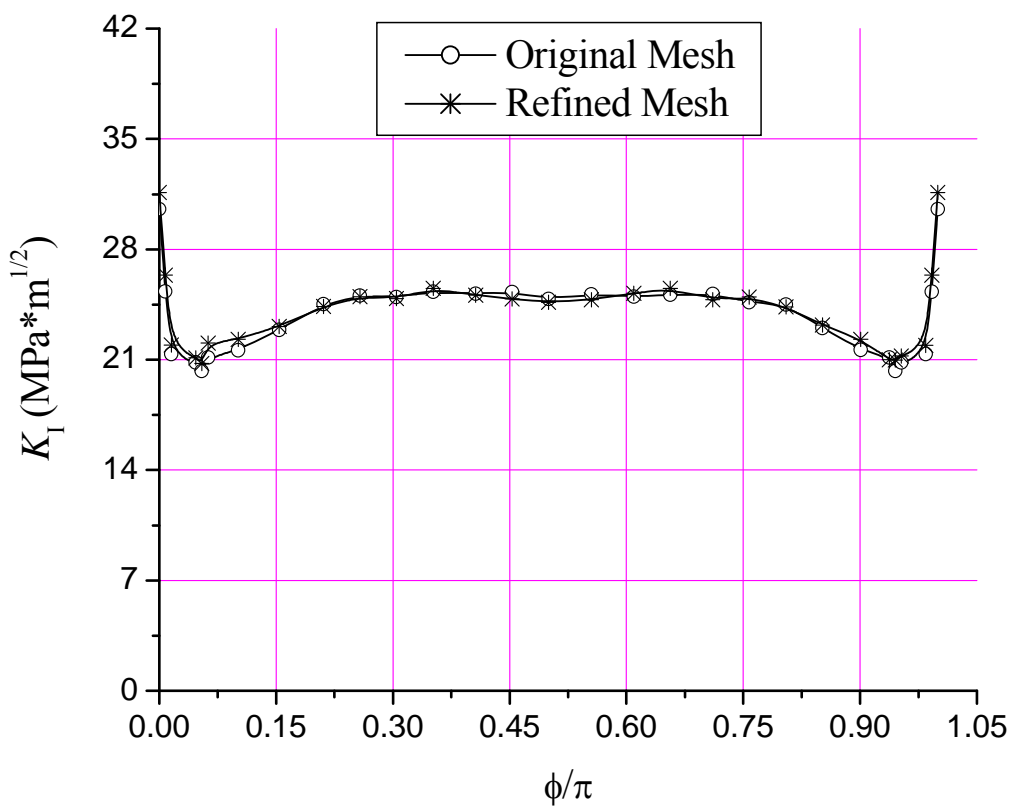

Figure 5. Convergence Test Results for the K-joint 


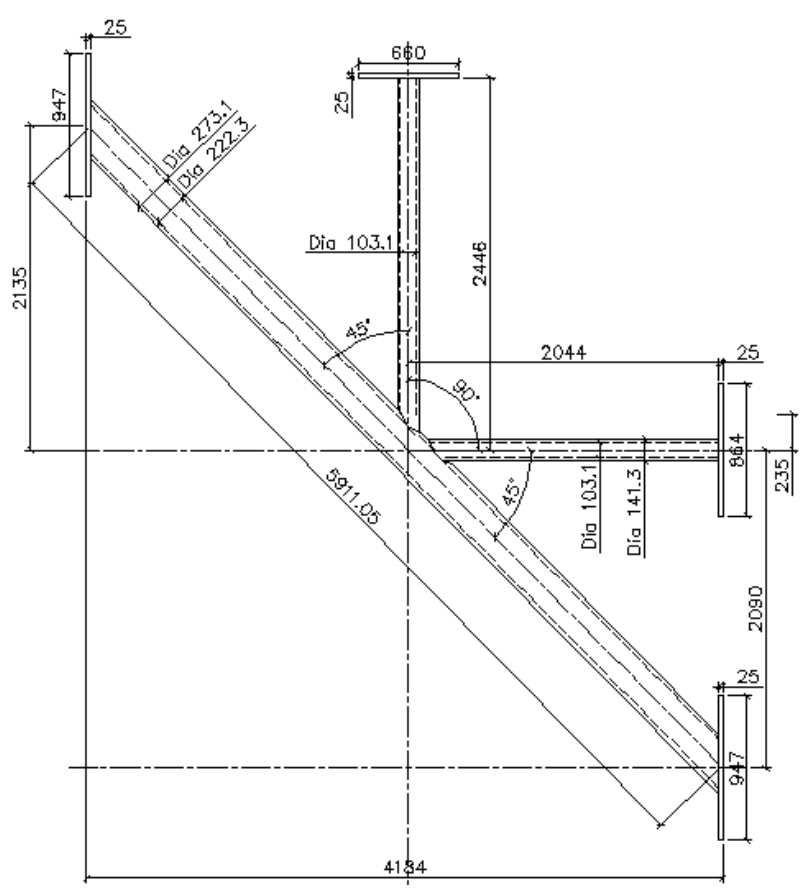

Figure 6. A Full-scale K-joint Specimen

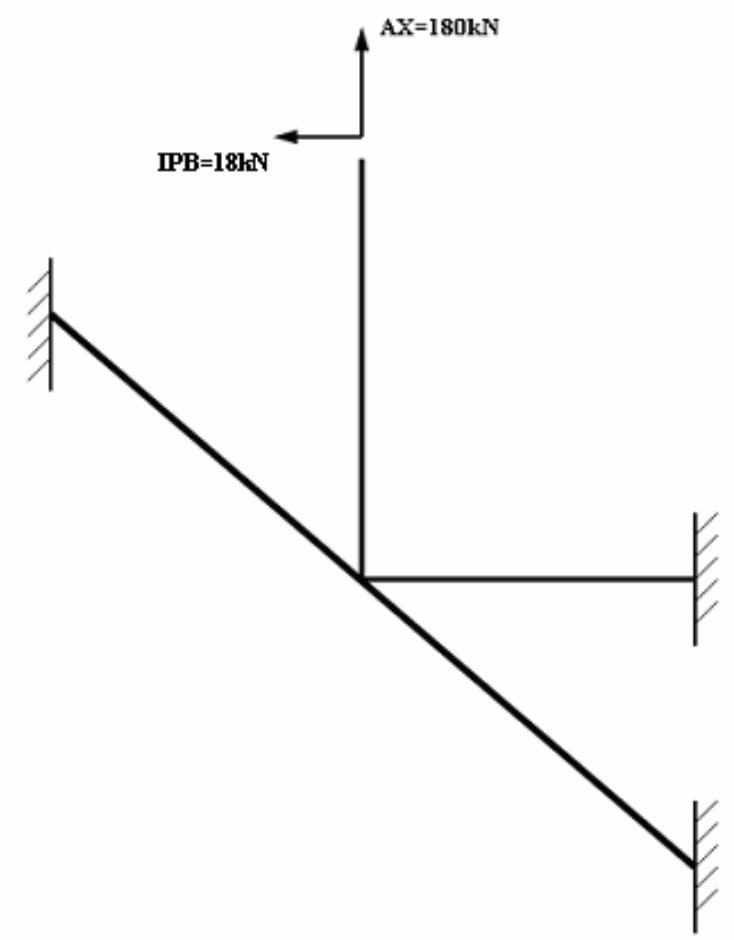

Figure 7. Load Cases and Boundary Conditions of the K-joint 


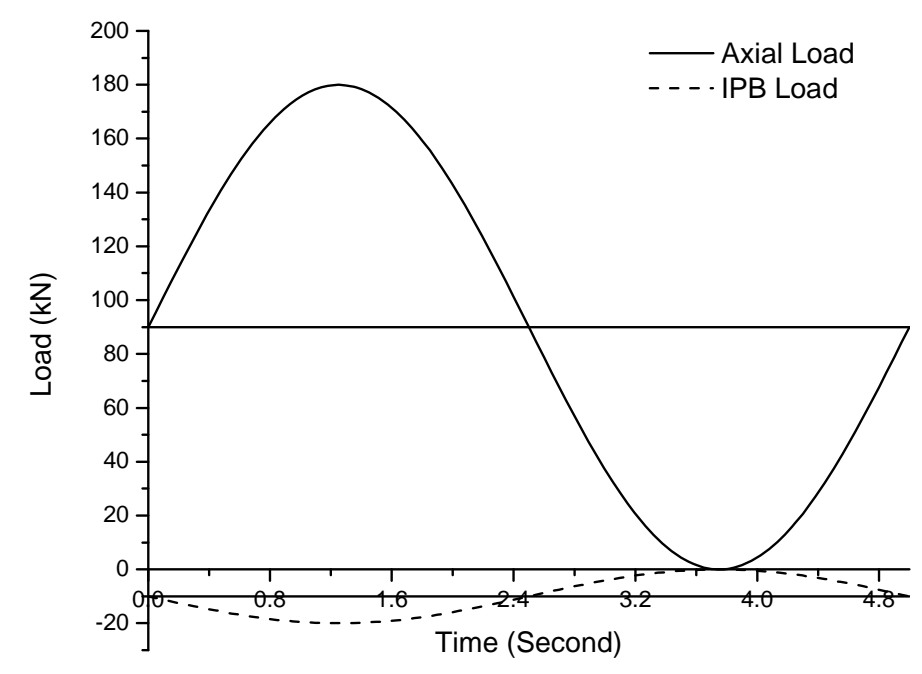

Figure 8. The Cyclic Loads applied in the Fatigue Test

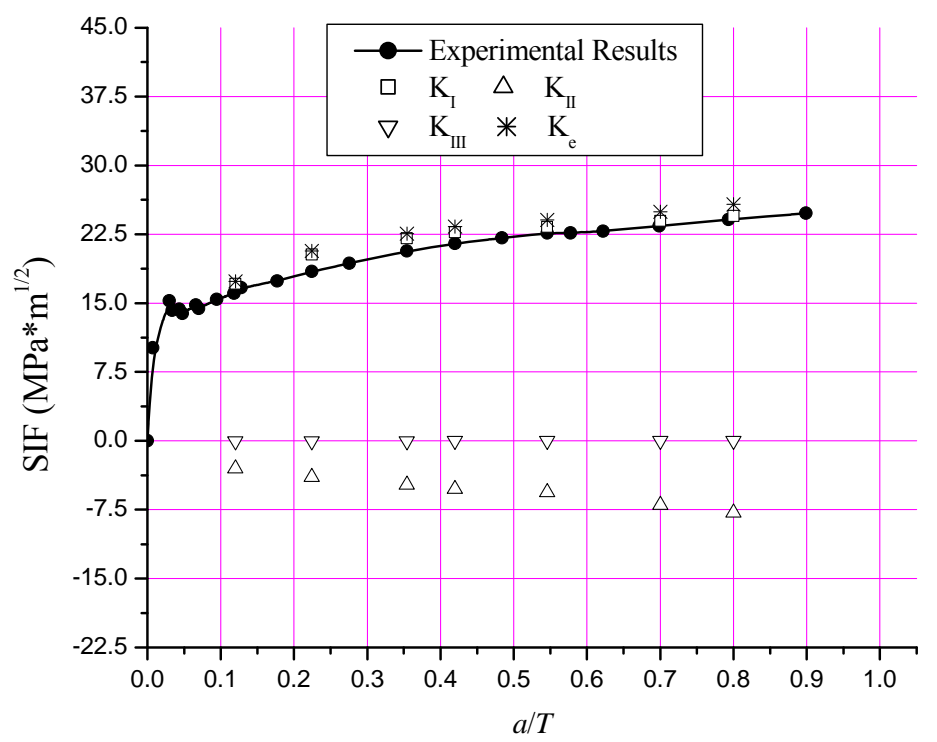

Figure 9. Comparison of the Stress Intensity Factors between Numerical and Experimental Results

For the past decades, several alternative methods have been used to estimate the stress intensity factors of a semi-elliptical surface crack in tubular K-joints. Thorpe [8] proposed an equation to predict the stress intensity factors of tubular joints by averaging the surface stress at the crack position over the crack length and simplifying the through-wall stress distribution into membrane and bending components. Haswell and Hopkins [9] and Myers [10] evaluated this model and found that this model generally over-predicts the stress intensity factors for all crack depths. Haswell and Hopkins [9] concluded that it was due to not including the geometry dependent compliance effects in the model. To avoid this over-prediction, other researchers (Burderkin et al. [11], Bowness and Lee [12]) proposed another correction factor called $M_{\mathrm{k}}$, the weld toe correction factor used to modify the flat plate model. Subsequently, Bowness and Lee [13] extended this method by including several correction factors, and later Lee and Bowness [14] proposed the model by representing it as a single parametric equation. This so-called indirect method is a very convenient method to use for estimating the stress intensity factor of a semi-elliptical surface crack in any tubular joint. This method has been 
adopted in the BS7910-Amendment 1 [15] codes of practice several years ago.

In this study, a total of 1024 models of cracked tubular K-joints covering a wide range of geometrical parameters and crack shapes are analyzed again using both the direct and indirect methods. The influence the geometrical parameters on the stress intensity factors at the deepest point as well as at the crack ends are investigated, and the modification factor $Y$ values which takes into account of joint geometry, crack size and loading cases, are then compared directly using both methods.

\section{TUBULAR K-JOINT CONFIGURATIONS}

For brevity in design and analysis, the geometry of a typical tubular K-joint can be simplified by expressing it as dimensionless parameters. Figure 10 shows the definition of these notations of geometrical parameters which are commonly used in practice. Hence, the characteristics of a K-joint can be described by normalized parameters, such as $\alpha, \beta, \gamma$ and $\tau$, and other parameters such as intersecting angle, $\theta$, and eccentricity, $e$. Using this method, the joints having the same parameters of $\alpha, \beta, \gamma, \tau, \theta$ and $e$ will be defined as the same model even though they have different diameters, thicknesses and lengths. Even if the joints have different scales, the numerical results will be the same for the same normalized parameters used in the analysis. This has been proved indispensable in generalizing results from one situation to another, and in scaling up the results of the scaled model tests (Marshall [16]).

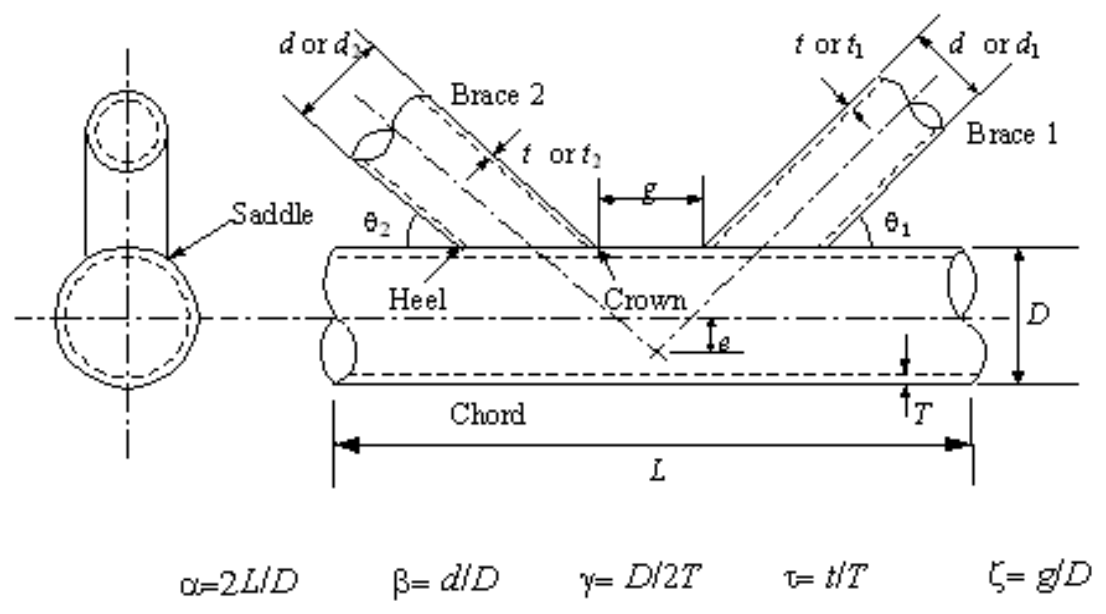

Figure 10. Notations of Geometrical Parameters in a Tubular K-joint

In practice, tubular K-joints are predominantly subjected to balanced axial loads as shown in Figure 11 where tension load is applied at the end of one brace member and compression load is applied at the end of the other brace member. When the intersecting angles, $\theta_{1}$ and $\theta_{2}$ between the chord and the two braces are equal, the tension and compression loads are equal in magnitude. For a tubular K-joint subjected to the balanced axial loads, the nominal stress is defined as

$\sigma_{\mathrm{n}}=\frac{4 F}{\left(\pi\left[d^{2}-(d-2 t)^{2}\right]\right)}$

where $d$ and $t$ are the diameter and the thickness of the brace member respectively. 


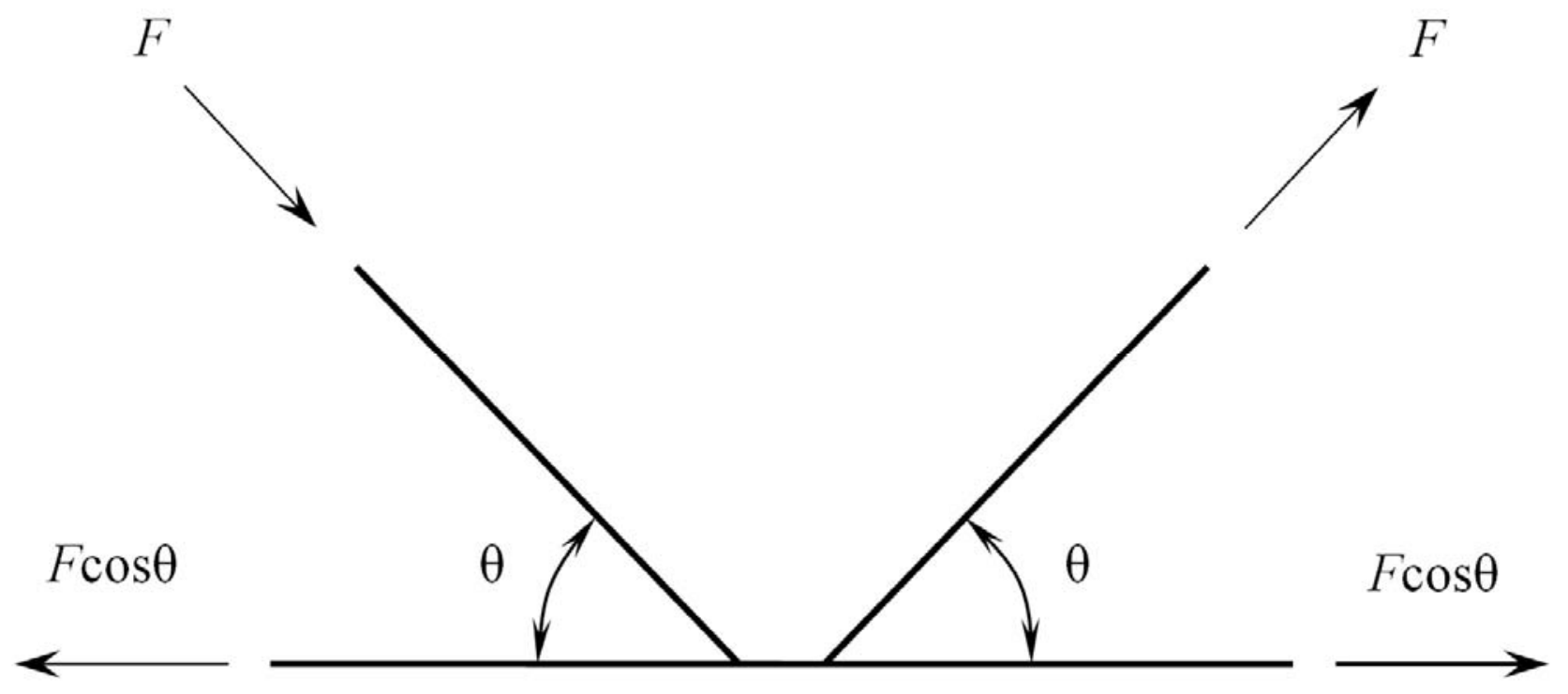

Figure 11. A Tubular K-joint subjected to Balanced Axial Loads

The general method to predict the stress intensity factor of a surface crack in any tubular joint is to provide a parametric equation. The most frequently used general parametric equation is given by

$K=Y \sigma_{\text {nom }} \sqrt{\pi a}$

where $\sigma_{\text {nom }}$ is the nominal stress and $a$ is the depth of a surface crack. $Y$ is called a modification factor, the non-dimensional $K$, which takes into account for the influence of the specimen geometry, crack profile and loading conditions.

Generally, the modification factor $Y$ is a function of joint geometry, crack size and structural restraints. Chong Rhee et al. [17] decomposed $Y$ into three factors as follows:

$Y=Y_{\mathrm{g}} Y_{\mathrm{s}} Y_{\mathrm{i}}$

where $Y_{\mathrm{g}}$ is the joint geometry factor which considers the effects of $\beta, \gamma$ and $\tau, Y_{\mathrm{s}}$ is the crack size factor which considers the effects of $a / T$ where $T$ is the chord thickness, and $c / a$ where $c$ is the half crack length, and $Y_{\mathrm{i}}$ is the joint and the crack coupling factor. Huang [18] added another factor $Y_{\theta}$ in his study, and this factor reflects the effect of the intersecting angle $\theta$. The complete modification factor can then be expressed as

$Y=Y_{\mathrm{g}} Y_{\mathrm{s}} Y_{\mathrm{i}} Y_{\theta}$

The influence of loading conditions on the stress intensity factors is taken care in the nominal stress, $\sigma_{\text {nom }}$. 
Based on the effectiveness and accuracy of the generated models discussed earlier, a parametric study of 1024 numerical models is carried out in this study. In the study, the K-joints are subjected to balanced axial loads only, and the range of geometrical parameters used in the finite element analyses is tabulated in Table 1.

Table 1. Range of Geometrical Parameters of the K-joint Models

\begin{tabular}{ccccccc}
\hline$\gamma$ & $\tau$ & $\theta_{1}$ & $\theta_{2}$ & $c / a$ & $a / T$ & $\beta$ \\
\hline 12,18, & $0.25,0.5$, & $45^{\circ}$ & $45^{\circ}$ & 5,6, & $0.1,0.3$, & $0.3,0.4$, \\
24,30 & $0.75,1.0$ & $45^{\circ}$ & $45^{\circ}$ & 7,8 & $0.5,0.7$ & $0.5,0.6$ \\
\hline
\end{tabular}

3.

\section{LEE AND BOWNESS (2001) EQUATION}

In the standard crack handbooks, there are no explicit SIF solutions for any tubular joint including the $\mathrm{K}$-joint. This is mainly due to the complexity of the geometry and loading conditions of any tubular joint containing a surface crack. Although many attempts have been made in the past decades to model fatigue performance of cracked tubular joints by using a variety of methods; there is still no accepted benchmark solution which can be used for comparison purposes. To date, a technique of using a flat plate model with relevant correction factors is still being used by many researchers. It is based on the SIF solutions of plain plate of Newman and Raju [19] with correction factors embedded into the equation (Bowness and Lee [13], Lee and Bowness [14]). These factors consider the effects of the geometry, the weld size and the load cases. This so-called indirect method is easy to apply because it is based on a flat plate solution, and there is no need to model the complex 3D surface crack in the tubular joints. However, one of the major drawbacks is that it can not accurately capture the load shedding present in the tubular joints. Furthermore, the fatigue crack propagation behaviour in a real tubular joint (Huang [18]) is known to be significantly different from that of a similar defect in a flat plate due to different structural restraint conditions.

\subsection{Flat Plate Models}

A flat plate model is based on the stress intensity factor of a surface crack in a finite plate subjected to tension and bending loads (Newman and Raju [19]). The empirical equation is given as follow:

$K=\left(S_{\mathrm{t}}+H S_{\mathrm{b}}\right) \sqrt{\frac{\pi a}{Q}} F\left(\frac{a}{t}, \frac{a}{c}, \frac{c}{b}, \phi\right)$

where $K$ is Mode-I stress intensity factor, $S_{\mathrm{t}}$ is the tension stress in the plate, $H$ is a correction factor, $S_{\mathrm{b}}$ is the bending stress on the plate surface, $Q$ is the shape factor for semi-elliptical defect, $F$ is the plain plate geometric factor, $a$ is the crack depth, $t$ is the plate thickness, $c$ is the crack half width, $b$ is the plate width, and $\phi$ is the elliptical integral. The expressions of $H, Q$ and $F$ can be found in paper by Newman and Raju [19].

Based on Eq. 5, Thorpe [8] proposed an equation to predict the stress intensity factors of tubular joints by averaging the surface stress at the crack position over the crack length and simplifying the through-wall stress distribution into membrane and bending components. This equation is given in the form of 


$$
K=\left(M_{\mathrm{m}} \sigma_{\mathrm{m}}+M_{\mathrm{b}} \sigma_{\mathrm{b}}\right) \sqrt{\frac{\pi a}{Q}}
$$

where $K$ is the Mode-I intensity factor, $M_{\mathrm{m}}$ and $M_{\mathrm{b}}$ are the plain plate shape factors for tension and bending respectively, $\sigma_{\mathrm{m}}$ and $\sigma_{\mathrm{b}}$ are the membrane and bending stresses respectively. Haswell and Hopkins [9] and Myers [10] evaluated this model and found that this model generally over-predicts the stress intensity factors for all crack depths. Haswell and Hopkins [9] concluded that it was due to not including the geometry dependent compliance effects in the model.

To avoid this over-prediction, some earlier researchers (Burdekin et al. [11]; Bowness and Lee [20]) proposed another correction factor which is called $M_{\mathrm{k}}$, the weld toe correction factor. This factor is defined as

$$
M_{\mathrm{k}}=\frac{K_{\text {in plate with attachment }}}{K_{\text {in same plate but with no attachment }}}
$$

The expression of $M_{\mathrm{k}}$ was given by Burdekin et al. [11] and Bowness and Lee [12].

After introducing the weld toe magnification factor $M_{\mathrm{k}}$ into the equation, the stress intensity factors of any tubular joint can be expressed in the following form as

$$
K=\left(M_{\mathrm{km}} M_{\mathrm{m}} \sigma_{\mathrm{m}}+M_{\mathrm{kb}} M_{\mathrm{b}} \sigma_{\mathrm{b}}\right) \sqrt{\frac{\pi a}{Q}}
$$

Subsequently, Lee and Bowness [14] approximated Eq. 8 as follow:

$$
K \approx\left(M_{\mathrm{km}} M_{\mathrm{m}} \mathrm{SCF} \times(1-\mathrm{DOB})+M_{\mathrm{kb}} M_{\mathrm{b}} \mathrm{SCF} \times \mathrm{DOB}\right) \sigma_{\mathrm{nom}} \sqrt{\pi a}
$$

where $a$ is the crack depth, $M_{\mathrm{k}}$ is the weld toe magnification factors, $M$ is the plain plate shape factor, and the subscripts $m$ and $b$ denote membrane and bending load respectively. SCF is the stress concentration factor and DOB is the degree of bending at the would-be location of the crack, and $\sigma_{\text {nom }}$ is the nominal stress in the reference brace of the joint.

As DOB, SCF and $\sigma_{\text {nom }}$ are all obtained from uncracked tubular joints, and $M_{\mathrm{kj}}, M_{\mathrm{j}}(\mathrm{j}=\mathrm{m}, \mathrm{b})$ can be calculated from parametric equations, it is clear that Eq. 9 is a very convenient method to use for estimating the stress intensity factors of any tubular K-joint because it avoids the complexity of generating the mesh of the surface crack. However, the actual surface crack along the weld in a tubular K-joint is shown to be a double-curved in shape (Bowness and Lee [20]), and the geometry of the intersecting curve has an influence on the stress intensity factor values. Another point is that the stress distribution along the weld toe is completely different from the stress distribution of a surface crack in a plain plate. As a result, the stress distribution will influence the stress intensity factors, and hence the crack propagation rate of the K-joint. 
Up to now, Eq. 9 is still being used by researchers to estimate the stress intensity factors of a surface crack in any tubular joint. In practice, it is convenient to use, but its accuracy and reliability has not been validated experimentally for the tubular K-joint.

\section{2}

\section{Calculation of SCF, DOB, $M_{\mathrm{k}}$ and $M$}

Eq. 9 is based on the analysis of the SCF and DOB values in uncracked tubular joints. Extensive research works on SCFs for tubular joint under axial load, in-plane bending and out-of-plane bending has been carried out in the past decades. Numerous SCF equations were proposed by many researchers (Efthymiou and Durkin [21], Smedley and Fisher [22]). Zhao et al. [23] has published a design guide for estimating SCF values using equations and design charts. The design guide covers all typical joint configurations used in practice such as the T-joint, Y-joint and $\mathrm{K}$-joint. Morgan and Lee [24] also proposed parametric equations to estimate the SCF values of the tubular K-joint.

All of the above equations can only predict the maximum SCF or SCFs at specific limited locations around the outer surface of the weld. For K-joints subjected to certain load cases, the SCF of the outer surface is usually different from the SCF of the inner surface of the chord. To solve this problem, Lee and Morgan [25] proposed a concept of degree of bending (DOB) which can be determined from the inner and outer surface stresses. Lee and Morgan [25] had also published their results based on the computation of SCFs for K-joints under axial load and in-plane bending. In order to simplify the determination of the membrane stress and bending stress, Lee and Bowness [26] proposed a concept of degree of bending (DOB). In Eq. 9, DOB is a parameter to measure the degree of bending of tubular joints, and it is defined as

$$
\mathrm{DOB}=\frac{\sigma_{\mathrm{b}}}{\sigma_{\mathrm{m}}+\sigma_{\mathrm{b}}}=1-\frac{1}{2} \frac{\mathrm{SCF}_{\text {inner }}}{\mathrm{SCF}_{\text {outer }}}
$$

where $\sigma_{\mathrm{b}}$ and $\sigma_{\mathrm{m}}$ are bending stress and membrane stress respectively. $\mathrm{SCF}_{\text {inner }}$ and $\mathrm{SCF}_{\text {outer }}$ are SCFs on the inner and outer surfaces of the chord. The same parametric equations of SCF and DOB are used in this study. Since the crack is symmetrical with respect to the crown, the crown SCF parametric equation is used for the crack deepest point. For the crack ends of the free surface which can be located anywhere along the weld toe, there is no specific SCF parametric equation that can be used in practice. In this paper, the crown SCF parametric equation is also used to calculate the $Y$ values of the crack tips. For the DOB, the same strategy is applied in this study.

Parametric equation of $M_{\mathrm{kj}}(\mathrm{j}=\mathrm{m}, \mathrm{b})$ are available in the literature (Bowness and Lee [20]), while parametric equation of $M_{\mathrm{j}}(\mathrm{j}=\mathrm{m}, \mathrm{b})$ can be found in the other literature (Newman and Raju [19]) or from Eq. 5.

\section{4.}

\section{DIRECT AND INDIRECT METHODS}

The stress intensity factors of a surface crack in a tubular K-joint are obtained directly from the generated model used in this study. In order to assess the accuracy of Eq. 9, the stress intensity factor values at the deepest point and at the crack ends of the surface cracks are calculated using both the direct and indirect methods. The two sets of results are tabulated in Table 2 together with the experimental results. It appears that Eq. 9 always produces higher estimated values. Hence, Eq. 9 is very safe and conservative. 
As mentioned previously, the stress intensity factor of the surface crack in a tubular K-joint can be expressed as

$$
K=Y \sigma_{\text {nom }} \sqrt{\pi a}
$$

where $Y$ is a modification factor, $a$ is the depth of a surface crack and $\sigma_{\text {nom }}$ is the nominal stress.

In the assessment of the stress intensity factor, $Y$ is called the modification factor. According to Eq. 9 , the expression of $Y$ can be written as

$$
Y=M_{\mathrm{km}} M_{\mathrm{m}} \mathrm{SCF} \times(1-\mathrm{DOB})+M_{\mathrm{kb}} M_{\mathrm{b}} \mathrm{SCF} \times \mathrm{DOB}
$$

Table 2. Comparison of SIF Values at the Deepest Point of a K-joint Specimen

\begin{tabular}{cccc}
\hline $\mathrm{a} / \mathrm{T}$ & \multicolumn{3}{c}{$\mathrm{SIF}\left(\mathrm{MPa}_{\mathrm{m}}^{\mathrm{1} / 2}\right)$} \\
\cline { 2 - 4 } & J-integral & Equation $(9)$ & Experimental Results \\
\hline 0.12 & 17.36 & 23.45 & 16.32 \\
0.22 & 20.69 & 26.34 & 18.44 \\
0.35 & 22.58 & 27.56 & 20.66 \\
0.42 & 23.33 & 28.74 & 21.49 \\
0.55 & 24.05 & 30.12 & 22.62 \\
0.71 & 24.97 & 31.22 & 23.71 \\
0.82 & 25.74 & 31.81 & 24.54 \\
\hline
\end{tabular}

In the analysis, $Y$ can be obtained directly by using the stress intensity factor values divided by $\sigma_{\text {nom }} \sqrt{\pi a}$. The two sets of $Y$ values can then be compared directly. In the parametric study, 1024 models with different geometrical parameters and crack shapes shown in Table 1 have been analyzed again. The numerical results of these models are used to assess the accuracy of the direct and indirect methods in this study.

\subsection{Effect of Geometrical Parameters on $Y$}

The first geometrical parameter to be investigated is $\gamma$ which is a ratio of chord radius to chord thickness. From Figs. 12(a) and 12(b), it can be seen that $Y$ increases gradually as $\gamma$ increases by keeping the other parameters of $c / a, a / T$ and $\beta$ constant. However, the actual $Y$ values obtained from the present study are much smaller than the corresponding values obtained from Eq. 12. This means that Eq. 12 produces relatively conservative estimation of stress intensity factor values. The trends of the graphs are consistent and reasonable. Figs. 13(a) and 13(b) show the relationship between $Y$ and $\beta$ which is a ratio of brace diameter to chord diameter, while keeping the other parameters $c / a, \tau$ and $\gamma$ constant. It can be found that the trends of the graphs are consistent at the deepest, but different at the crack ends. In fact, $Y$ has an inverse tendency at the crack ends as $\beta$ increases for the direct and indirect method. The effect of parameter $\tau$ on the $Y$ is illustrated in Figs. 14(a) and 14(b). It is clear that as $\tau$ increases $Y$ increases too. The trends of the graphs are the same at both the deepest point and crack ends. 


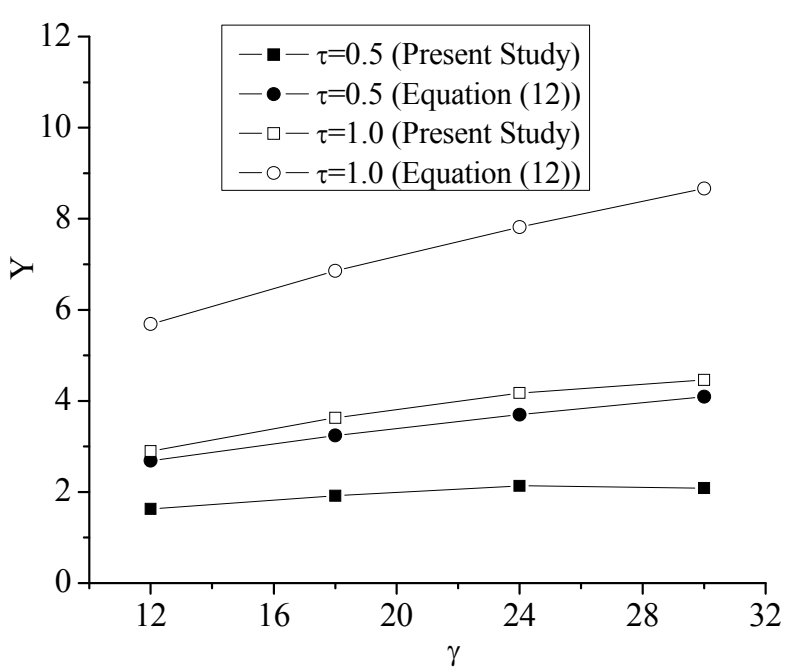

(a) at the deepest point

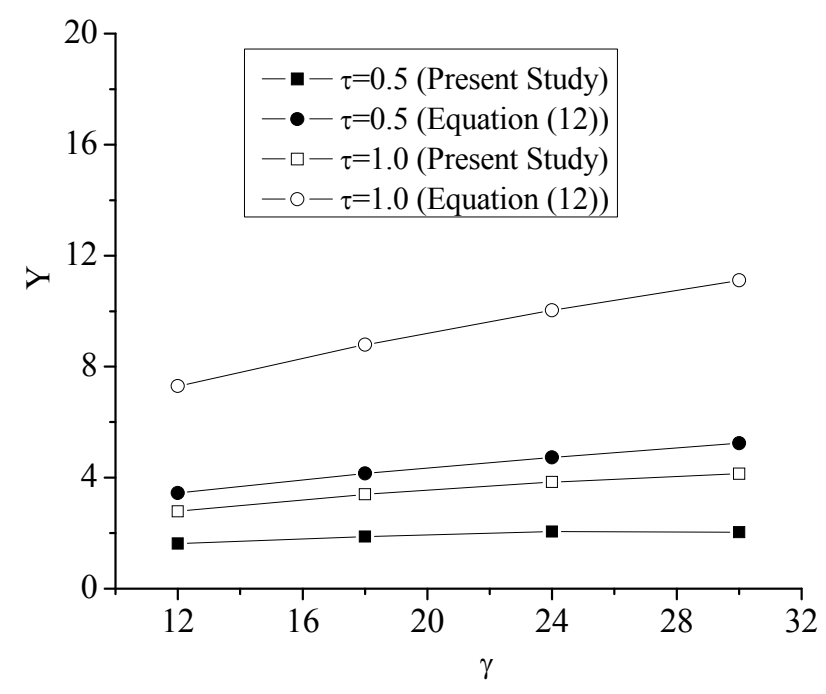

(b) at the crack ends

Figure 12. Effect of $\gamma$ on $Y(c / a=5, a / T=0.1, \beta=0.3)$ 




(a) at the deepest point

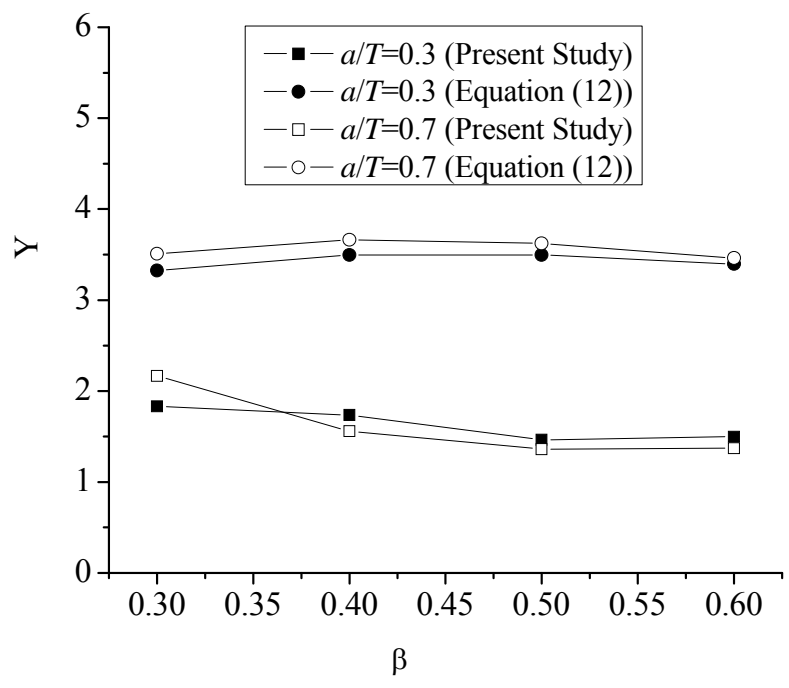

(b) at the crack ends

Figure 13. Effect of $\beta$ on $Y(\gamma=18, \tau=0.5, c / a=6)$

\section{2}

\section{Effects of Crack Shapes on $Y$}

The effects of the crack shape on $Y$ are illustrated in Figs. 15(a), 15(b), 16(a) and 16(b). Generally, $Y$ decreases as $a / T$ increases at the deepest point. Both methods produce the same conclusions. When $\beta$ is small, $Y$ decreases initially and then increases as $a / T$ increases. But when $\beta$ is large, $Y$ increases as $a / T$ increases. Hence, the trend of $Y$ is not distinct at the crack ends. The effect of $c / a$ on $Y$ is the opposite. When $c / a$ becomes larger, $Y$ increases at the deepest point and slightly decreases at the crack ends. It should be noted that the series of solid circle almost coincides with the series of the blank circle in Fig. 16(b) when $\beta$ is equal to 0.3. The effects of the crack shape on $Y$ values can then be generalized as: for a deeper crack, $Y$ at the deepest point is smaller and $Y$ at the crack ends is larger; for a shallow and longer crack, $Y$ at the deepest point is bigger and its value at the crack ends is smaller. 
From these results, it can be seen that both direct and indirect methods can provide the same prediction of the effects of the crack shapes on the $Y$ values at the deepest point, but very poor prediction are obtained at the crack ends. This may be because the crown SCF and DOB equations are used for the crack ends as the crack ends SCF and DOB equations are not readily available in the literature.

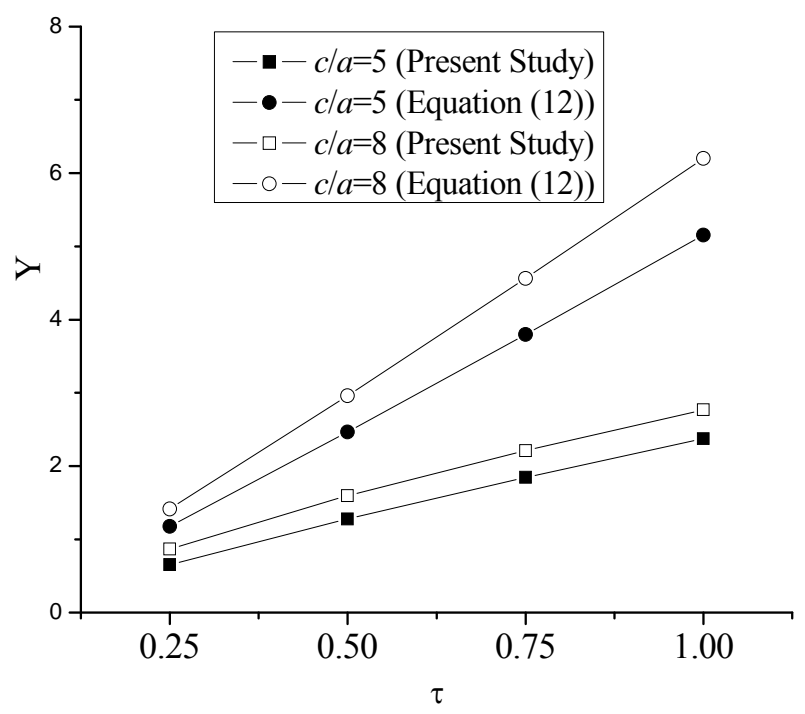

(a) at the deepest point

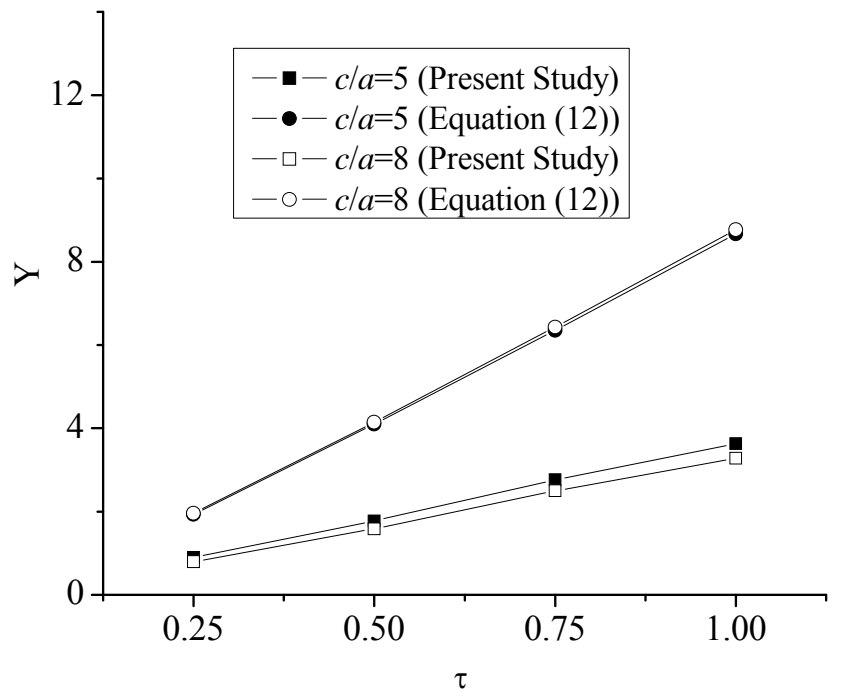

(b) at the crack ends

Figure 14. Effect of $\tau$ on $Y(\gamma=24, a / T=0.5, \beta=6)$ 


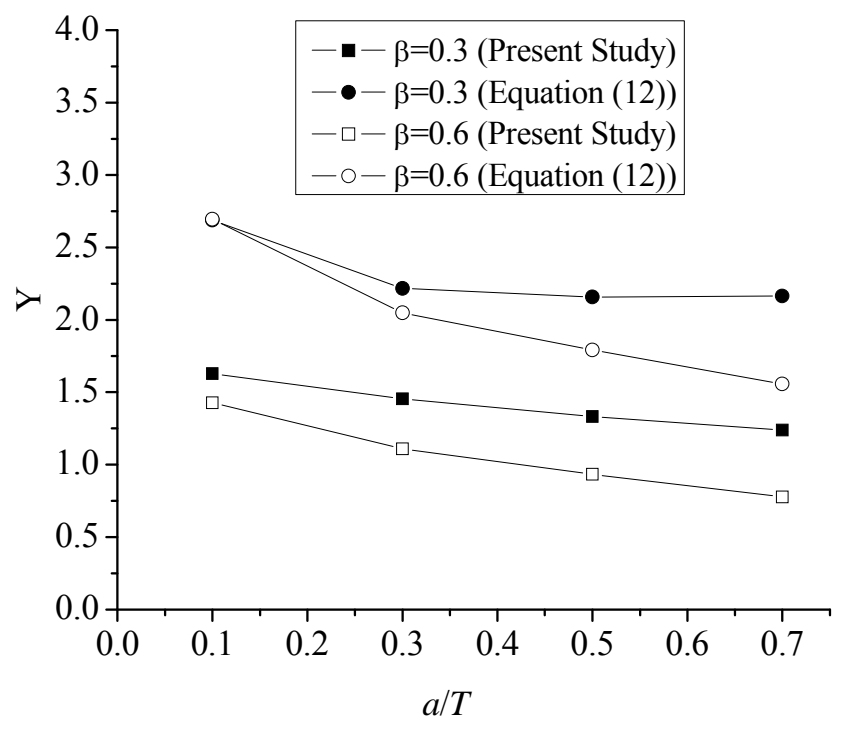

(a) at the deepest point

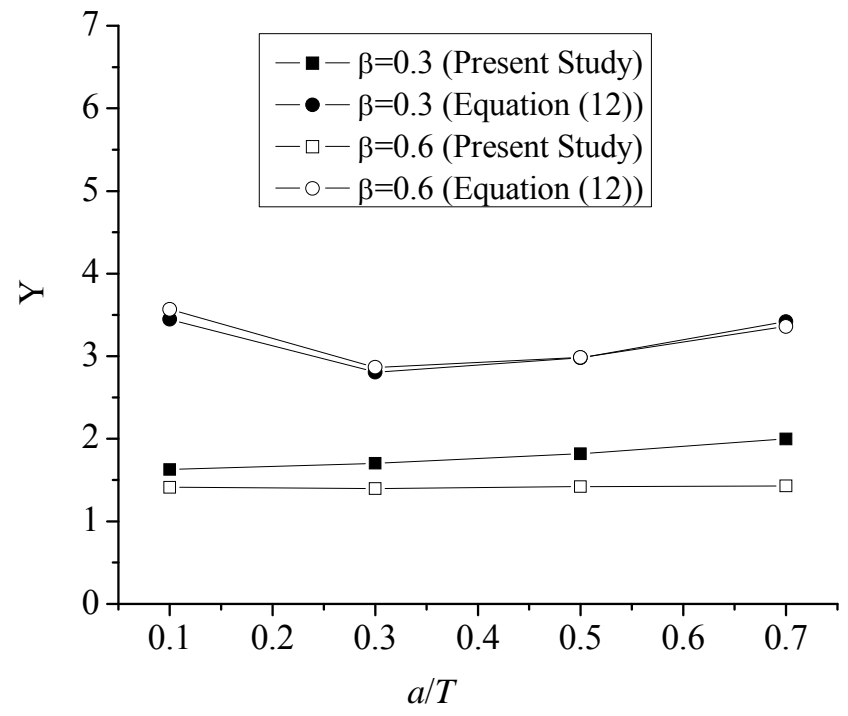

(b) at the crack ends

Figure 15. Effect of $a / T$ on $Y(\gamma=12, \tau=0.5, c / a=5)$

\section{3}

\section{Error Estimation Analysis}

To validate the accuracy of the Eq. 12, a comparison is carried out between the direct and indirect method results. An equation of relative error is introduced and defined as

Relative Error $=\frac{Y_{\mathrm{Equation}}-Y_{\mathrm{FE}}}{Y_{\mathrm{FE}}} \times 100 \%$ 
where $Y_{\text {Equation }}$ is the modification factor calculated using indirect method, and $Y_{\mathrm{FE}}$ is the modification calculated using direct method. Figure 17 shows the comparison results. From Figure 17, it can be seen that the $Y_{\text {Equation }}$ calculated using the Eq. 12 is very conservative; it overestimates the stress intensity factor values by as much as $190.4 \%(\beta=0.5, \gamma=30, \tau=0.5, a / T=0.1, c / a=5)$ at the deepest point, and $390.7 \%(\beta=0.4, \gamma=30, \tau=0.5, a / T=0.5, c / a=8)$ at the crack ends of the surface crack respectively.

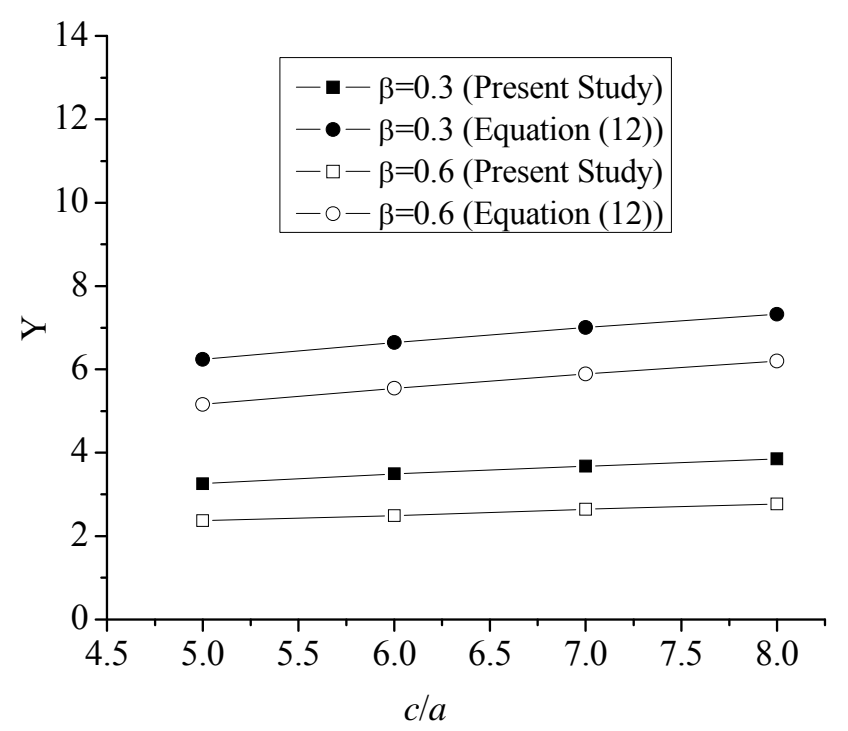

(a) at the deepest point

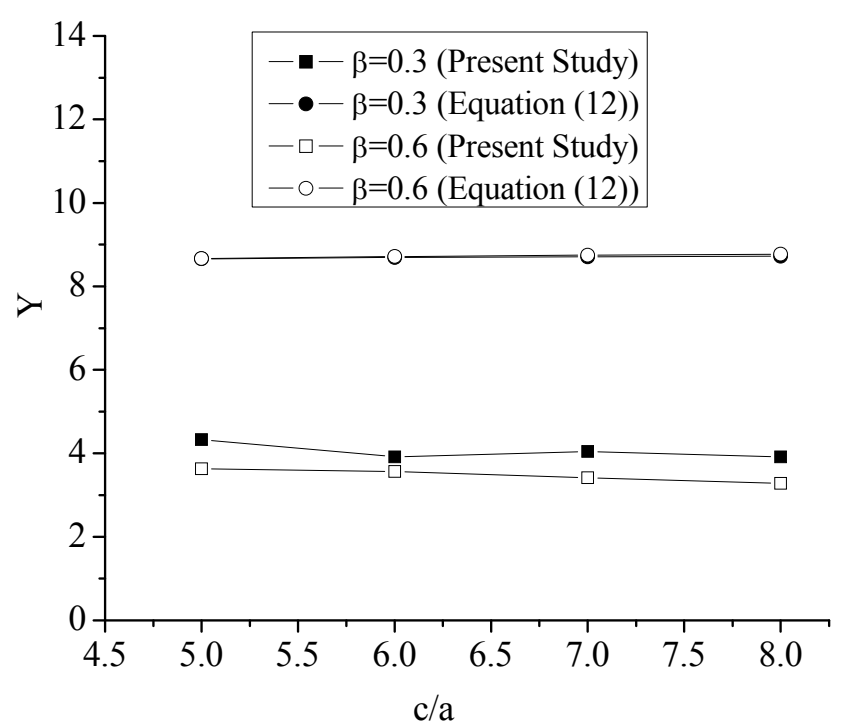

(b) at the crack ends

Figure 16. Effect of $c / a$ on $Y(\gamma=24, \tau=1.0, a / T=0.5)$ 


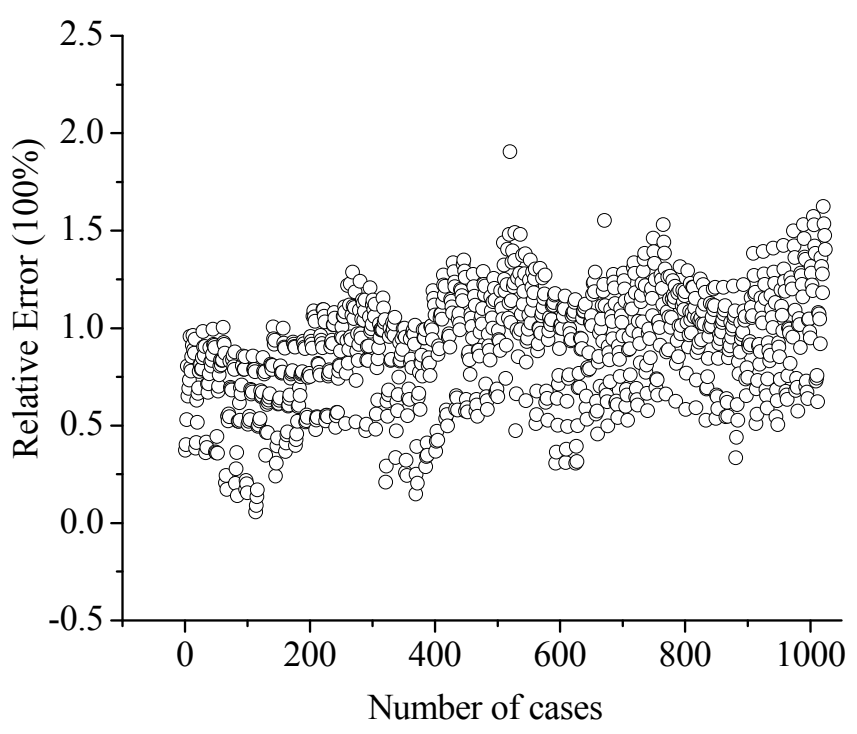

(a) at the deepest point

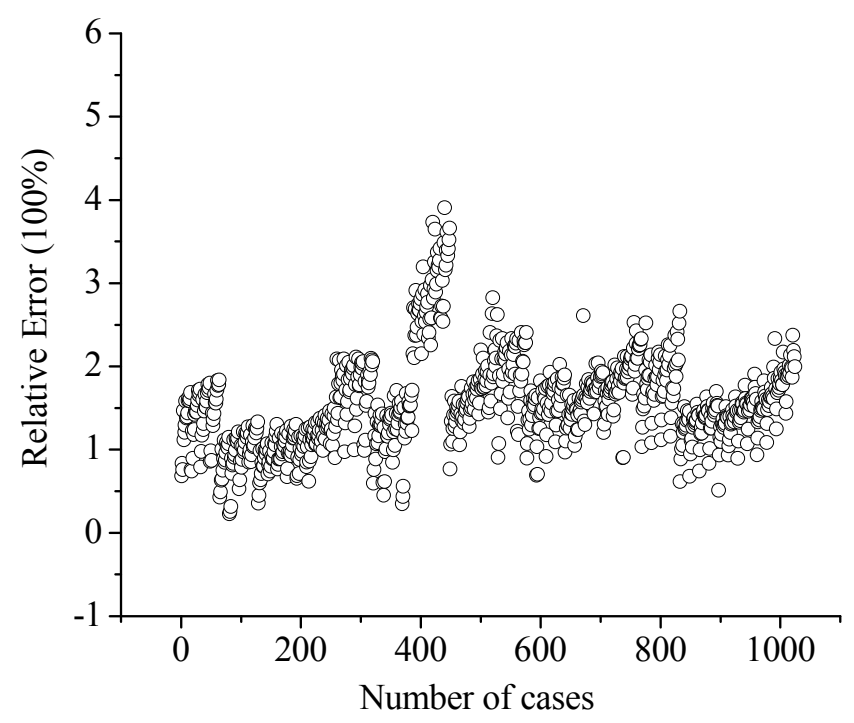

(b) at the crack ends

Figure 17. Error Analysis of Numerical Models

\section{5.}

\section{CONCLUSIONS}

A numerical model of a tubular K-joint containing a semi-elliptical surface crack has been presented and described briefly in this paper. The surface crack is modeled explicitly in the cracked joint. It is shown that the direct method can produce accurate stress intensity factors at the deepest point and also at the crack ends of the surface crack. In the indirect method, a T-butt solution used in conjunction with the stress concentration factors (SCFs) and degree of bending (DOB) is used to estimate the stress intensity factor values at the deepest point and also at the crack ends. The accuracy of both methods is assessed by comparing the modification factor $Y$ values. From the parametric study of 1024 models, it is concluded that both the direct method and the indirect method can produce safe estimation of stress intensity factor values of a surface crack in a tubular K-joint. However, the 
indirect method is very conservative, and it overestimates the stress intensity factor values by as much as $190.4 \%(\beta=0.5, \gamma=30, \tau=0.5, a / T=0.1, c / a=5)$ at the deepest point, and $390.7 \%(\beta=0.4, \gamma=30$, $\tau=0.5, a / T=0.5, c / a=8)$ at the crack ends of the surface crack respectively.

\section{Nomenclatures}

\begin{tabular}{|c|c|}
\hline$a$ & crack depth \\
\hline$b$ & plate width \\
\hline C & half crack length \\
\hline DOB & degree of bending \\
\hline$d$ & brace diameter \\
\hline$D$ & chord diameter \\
\hline$e$ & eccentricity \\
\hline F & axial load \\
\hline$g$ & gap distance \\
\hline$H$ & correction factor \\
\hline$J$ & $J$-integral \\
\hline$K_{\mathrm{I}}$ & Mode-I stress intensity factor \\
\hline$K_{\text {II }}$ & Mode-II stress intensity factor \\
\hline$K_{\text {III }}$ & Mode-III stress intensity factor \\
\hline$K_{\mathrm{e}}$ & effective stress intensity factor \\
\hline$L$ & chord length \\
\hline$M_{\mathrm{m}}$ & plain plate shape factor for tension \\
\hline$M_{\mathrm{b}}$ & plain plate shape factor for bending \\
\hline$M_{\mathrm{k}}$ & weld toe correction factor \\
\hline$M_{\mathrm{km}}$ & weld toe correction factor due to membrane stress \\
\hline$M_{\mathrm{kb}}$ & weld toe correction factor due to bending stress \\
\hline$N$ & number of cycles \\
\hline$Q$ & shape factor \\
\hline$r$ & brace radius \\
\hline$R$ & chord radius \\
\hline $\mathrm{SCF}$ & stress concentration factor \\
\hline $\mathrm{SCF}_{\text {inner }}$ & SCF on the inner surface of the chord \\
\hline $\mathrm{SCF}_{\text {outer }}$ & SCF on the outer surface of the chord \\
\hline$S_{\mathrm{b}}$ & bending stress in the plate \\
\hline$S_{\mathrm{t}}$ & tension stress in the plate \\
\hline$t$ & plate thickness \\
\hline$T$ & chord thickness \\
\hline$Y$ & modification factor \\
\hline$Y_{\mathrm{g}}$ & joint geometry factor \\
\hline$Y_{\mathrm{s}}$ & crack size factor \\
\hline$Y_{\mathrm{i}}$ & joint and crack coupling factor \\
\hline$Y_{\theta}$ & intersecting angle factor \\
\hline$\alpha$ & a ratio of $2 L / D$ \\
\hline$\beta$ & a ratio of $d / D$ \\
\hline$\gamma$ & a ratio of $D / 2 T$ \\
\hline$\theta$ & intersecting angle between brace and chord \\
\hline$\sigma_{\text {nom }}$ & nominal stress \\
\hline$\sigma_{\mathrm{m}}$ & membrane stress \\
\hline$\sigma_{\mathrm{b}}$ & bending stress \\
\hline
\end{tabular}




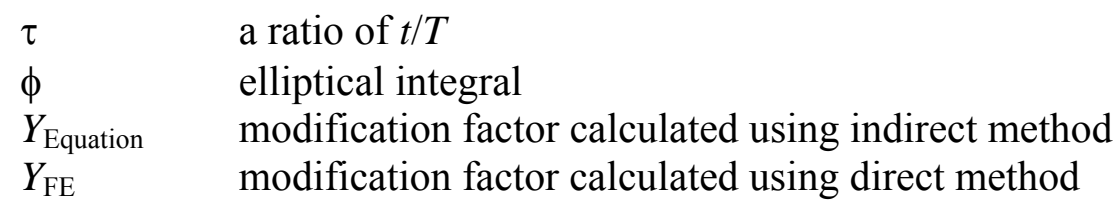

\section{REFERENCES}

[1] Cao, J.J., Yang, G.J. and Packer, J.A., "FE Mesh Generation for Circular Joints with or without Cracks", Proceeding of the 7th International Offshore and Polar Engineering Conference (ISOPE), USA, 1997, pp. 53-58.

[2] Bowness, D. and Lee, M.M.K., "The Development of an Accurate Model for the Fatigue Assessment of Doubly Curved Cracks in Tubular Joints", International Journal of Fracture, 1995, Vol. 73, pp. 129-47.

[3] Lie, S.T., Lee, C.K., Chiew, S.P. and Shao, Y.B., "Estimation of Stress Intensity Factors of Weld Toe Surface Cracks in Tubular K-Joints", 10th International Symposium on Tubular Structures, Madrid, Spain, 2003, pp. 347-355.

[4] Lie, S.T., Lee, C.K., Chiew, S.P. and Shao, Y.B., "Mesh Modelling and Analysis of Cracked Uni-planar Tubular K-joints", Journal of Constructional Steel Research, 2005, Vol. 61, No. 2, pp. 235-264.

[5] Shao, Y.B. and Lie, S.T., "Parametric Equation of Stress Intensity Factor for Tubular K-joint under Balanced Axial Loads", International Journal of Fatigue, 2005, Vol. 26, No. 6, pp. 666-679.

[6] Shao, Y.B., Lie, S.T. and Chiew, S.P., "Effect of Chord Length Ratio of Tubular Joints on Stress Concentration at Weld Region", Proceedings of the 12th International Symposium on Tubular Structures, Shanghai, China, 2008, pp. 375-379.

[7] Lie, S.T., Chiew, S.P., Lee, C.K. and Shao, Y.B., "Validation of a Surface Crack Stress Intensity Factors of a Tubular K-joint", International Journal of Pressure Vessels and Piping, 2005, Vol. 82, No. 8, pp. 610-617.

[8] Thorpe, T.W., "A Simple Model of Fatigue Crack Growth in Welded Joints", Offshore Technology Report, 1986, OTH 86255.

[9] Haswell, J. and Hopkins, P., "A Review of Fracture Mechanics Models of Tubular Joints", Fatigue and Fracture of Engineering Materials and Structures, 1991, Vol. 14, No. 5, pp. 483-497.

[10] Myers, P.T., "Corrosion Fatigue and Fracture Mechanics of High Strength Jack Up Steels", Ph.D. Thesis, University College London, London, UK, 1998.

[11] Burdekin, F.M., Chu, W.H., Chan, W.T.W. and Manteghi, S., "Fracture Mechanics Analysis of Fatigue Crack Propagation in Tubular Joints", International Conference on Fatigue and Crack Growth in Offshore Structures, London, UK, 1986.

[12] Bowness, D. and Lee, M.M.K., "Stress Intensity Factor Solutions for Semi-elliptical Weld-toe Cracks in T-butt Geometries", Fatigue and Fracture of Engineering Materials and Structures, 1996, Vol. 19, No. 6, pp. 787-797.

[13] Bowness, D. and Lee, M.M.K., "Prediction of Weld Toe Magnification Factors for Semi-elliptical Cracks in T-butt Joint", International Journal of Fatigue, 2000, Vol. 22, No. 5, pp. 369-387.

[14] Lee, M.M.K. and Bowness, D., "Prediction of Stress Intensity Factors in Semi-elliptical Weld Toe Cracks in Offshore Tubular Joints", Proceedings of the 9th International Symposium on Tubular Structures, Dusseldorf, Germany, 2001, pp. 299-308.

[15] BS7910-Amendment 1, "Guide to Methods for Assessing the Acceptability of Flaws in Metallic Structures”, British Standard Institution, London, UK, 2005. 
[16] Marshall, P.W., "Design of Welded Tubular Connections: Basis and Use of AWS Code Provisions", Elsevier Science Publishers, Amsterdam, The Netherlands, 1992.

[17] Chong, R.H., Han, S. and Gipson, G.S., "Reliability of Solution Method and Empirical Formulas of Stress Intensity Factors for Weld Toe Cracks of Tubular Joints", Proceedings of the 10th Offshore Mechanics and Arctic Engineering Conference, ASME, 1991, Vol. 3(B), pp. 441-452.

[18] Huang, Z.W., "Stress Intensity Factor of Cracked Steel Tubular T and Y-joints under Complex Loads”, Ph.D. Thesis, Nanyang Technological University, Singapore, 2002.

[19] Newman, J.C. and Raju, I.S., "An empirical Stress Intensity Factors Equation for the Surface Crack”, Engineering Fracture Mechanics, 1981, Vol. 15, No. 2, pp. 185-192.

[20] Bowness, D. and Lee, M.M.K., "Fatigue Crack Curvature under the Weld Toe in an Offshore Tubular Joint", International Journal of Fatigue, 1998, Vol. 20, No. 6, pp. 481-490.

[21] Efthymiou, M. and Durkin, S., "Stress Concentrations in T/Y and gap/overlap K-joints. Proceedings Conference on Behaviour of Offshore Structures, Delft, Elsevier Science Publishers, Amsterdam, The Netherlands, 1985, pp. 429-440.

[22] Smedley, P. and Fisher, P., "Stress concentration Factors for Simple Tubular Joints", Proceedings of the 1st International Offshore and Polar Engineering Conference, International Society of Offshore and Polar Engineers, Edinburgh, UK, 1991, pp. 475-483.

[23] Zhao, X.L., Herion, S., Packer, J.A., Puthli, R., Sedlacek, G., Wardenier, J., Weynand, K., van Wingerde, A. and Yeomans, N., "Design Guide for Circular and Rectangular Hollow Section Joints under Fatigue Loading. CIDECT Publication No. 8, TUV-Verlag, Germany, 2000.

[24] Morgan, M.R. and Lee, M.M.K., "Prediction of Stress Concentration Factors in K-joints under Balanced Axial Loading", Proceedings of the 7th International Symposium on Tubular Structures, Hungary, 1996, pp. 301-308.

[25] Lee, M.M.K. and Morgan, M,R., "Prediction of Stress Concentration Factors in On-plane Moment Loaded Tubular K-joints", Proceedings of the 8th International Symposium on Tubular Structures, Singapore, 1998, pp. 305-314.

[26] Lee, M.M.K. and Bowness, D., "Factors Affecting the Fracture Mechanics Assessment of a Cracked Offshore Tubular Joint", Proceedings of the 8th International Symposium on Tubular Structures, Singapore, 1998, pp. 353-359. 